\title{
Effect of Endogenous and Exogenous Urate on the Uricase Formation by Streptomyces sp. ${ }^{+}$
}

\author{
Yasuto Watanabe and Tatsuhiko OHE \\ Osaka Municipal Institute of Technology, Kitaku, Osaka
}

Received October 6, 1972

\begin{abstract}
Cells of a strain of Streptomyces sp. were incubated with an equivalent quantity of urate, xanthine, 6,8-dihydroxypurine or hypoxanthine in a medium deprived of other nitrogen source. The amount of uricase produced by these cells was shown to differ significantly, increasing in the following order of purine bases added to the medium: urate, xanthine, 6,8-dihydroxypurine and hypoxanthine. Of these was only urate indicated to be the inducer of uricase formation, and the difference in the quantity of uricase produced was found to be based on the duration of enzyme formation. The rate of uricase formation was essentially identical regardless of the purine bases supplied to cells.

Allantoin was accumulated in medium in remarkably different manners depending on the purine bases, which suggested the diversity in the mode of generation of urate in cells. Urate was generated at the slowest rate in the cells incubated with hypoxanthine, although the largest amount of uricase was produced. However, urate supplied to cells at the same rate but from medium failed to support the enzyme formation when the activity increased to a certain level. In order that the same amount of uricase was produced by the cells incubated with the different purine bases, the initial concentration of the purine bases should be raised so that they could remain in medium for the same incubation time.

Intracellular compartmentalization that might segregate endogenous and exogenous urate and might cause the difference in "effeciency" of these urate molecules as the inducer of uricase formation has been discussed.
\end{abstract}

Uricase formation of a strain of Streptomyces sp. has been found to be strongly repressed in growing cells cultivated in a peptone-glucose medium, ${ }^{1)}$ and to be derepressed in resting cells incubated in a medium deprived of nitrogen source. ${ }^{2)}$ The enzyme formation in resting cells has been shown to be evoked even in the absence of urate in medium, ${ }^{3)}$ and this uricase formation seems to be elicited by inducers derived through the endogenous catabolism of purine bases, although the constitutive level of the enzyme formation has remained to be studied. Oxidation of hypoxanthine to urate has been found to proceed by two suggestive ways of xanthine and of 6,8-dihydroxypurine simultaneously in this microorganism. ${ }^{4)}$

$\downarrow$ Studies on the Formation of Uricase by Streptomyces. Part V. See reference 5) for Part IV. A part of this report was presented at the Annual Meeting of the Agricultural Chemical Society of Japan held in Tokyo in April, 1971.
Addition of urate or its metabolic precursors to the incubation medium has resulted in remarkable promotion of uricase formation. ${ }^{3)}$ The amount of uricase produced, however, differed considerably depending on the purine bases, if they were added to give an equivalent concentration. The present paper describes the investigation which was undertaken to elucidate the cause of diversity in uricase formation by this microorganism incubated with different purine bases.

\section{MATERIALS AND METHODS}

A strain of Streptomyces sp., which had been isolated from soil as a strong uricase producer and stocked on a potato-agar slant, ${ }^{11}$ was used throughout the investigation. The microorganism was grown in a growth medium $(60 \mathrm{ml})$, consisting of $2 \%$ peptone, $3 \%$ glucose, $0.1 \% \mathrm{~K}_{2} \mathrm{HPO}_{4}, 0.05 \% \mathrm{MgSO}_{4} \cdot 7 \mathrm{H}_{2} \mathrm{O}$ and $0.05 \% \mathrm{NaCl}$, and adjusted to $\mathrm{pH} 7$. Cultivation was performed at $27^{\circ} \mathrm{C}$ for $36 \mathrm{hr}$ with shaking. Cells were harvested on a Buchner funnel and washed with water. 
Washed cells $(0.5 \mathrm{~g}$ in wet weight) were suspended in an incubation medium ( $\mathrm{pH} 7$ ), containing 1 mmole of potassium phosphate, $400 \mu$ moles of glucose, $200 \mu$ moles of $\mathrm{MgCl}_{2}$ and $40 \mu$ moles of one of the following purine bases in $20 \mathrm{ml}$ : urate, xanthine, 6,8-dihydroxypurine and hypoxanthine. Incubation was carried out at $30^{\circ} \mathrm{C}$ with shaking. Aliquots of the incubation mixture were taken at intervals and filtered through filter paper.

Ultraviolet absorption of the filtrate was measured at pH 7. Purine bases were analyzed by a Hitachi Liquid Chromatograph 034 as previously reported. ${ }^{4}$ ? Samples (the filtrate) were applied on a column of Dowex 1-X2 and eluted with $0.3 \mathrm{M} \mathrm{NaCl}$ in $0.05 \mathrm{M}$ phosphate buffer ( $\mathrm{pH} 7.6$ ). Absorbances of the eluate were measured at 260, 270 and $290 \mathrm{~m} \mu$. Allantoin in the filtrate was determined by a Hitachi Amino Acid Analyzer KLA-3B as previously described. ${ }^{2 !}$ Samples were loaded on a $50-\mathrm{cm}$ column and eluted with citrate buffer ( $\mathrm{pH} 3.25$ ).

Cells were disrupted sonically to extract uricase, and the enzyme activity in the sonic extract was assayed spectrophotometrically according to the procedures previously described. ${ }^{11}$ One unit was defined as the amount of enzyme required to catalyze the oxidation of $1 \mu$ mole of urate per min under the assay conditions used, and specific activity was expressed in units per $g$ of wet cells.

6,8-Dihydroxypurine was prepared as reported in the previous paper." Uric acid, xanthine and hypoxanthine were purchased from Wako Pure Chemical Industries, Ltd. Other reagents used were the highest grade commercially available.

\section{RESULTS}

Ultraviolet absorbances of the medium, in

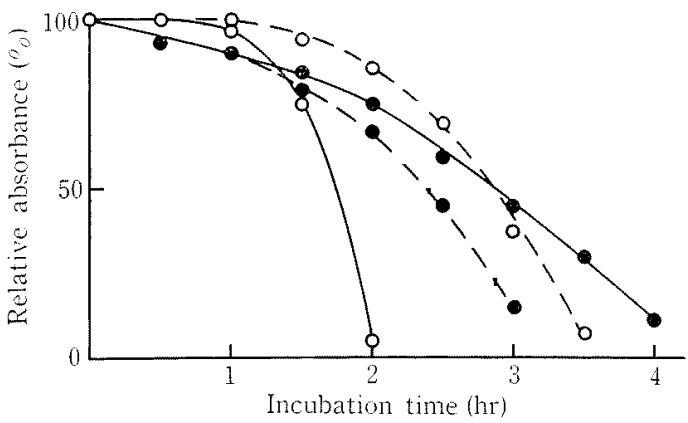

Fig. 1. Decrease in Ultraviolet Absorption of the Medium in which Cells were Incubated with Various Purine bases.

Absorbance of the medium containing urate, xanthine, 6,8-dihydroxypurine or hypoxanthine was determined at $290 \bigcirc-0,270-\cdots, 260 \bigcirc-\cdots 0$ or $250 \mathrm{mu}$ respectively. which cells were incubated with one of the following purine bases: urate, xanthine, 6,8dihydroxypurine and hypoxanthine, were determined at 290, 270, 260 and $250 \mathrm{~m} \mu$, respectively. As shown in Fig. 1, the decrease profile of absorbances during incubation was found to depend on purine bases used. The cells grown for $36 \mathrm{hr}$ under the conditions stated in Method possessed significant activities of oxidizing xanthine and hypoxanthine, but little of oxidizing urate and 6,8-dihydroxypurine. ${ }^{4}$

Time courses of uricase formation in the cells during incubation with these purine bases are shown in Fig. 2. It was found, by comparing with Fig. 1, that the enzyme activity increased until ultraviolet absorption disappeared from the medium regardless of purine bases added. The maximum activity attained in the cells by incubation with urate was 2.8 units per $\mathrm{g}$ of wet cells after $2.5 \mathrm{hr}$, with xanthine 5.4 units after $3 \mathrm{hr}$, with 6,8 dihydroxypurine 5.6 units after $3.5 \mathrm{hr}$ and with hypoxanthine 9.2 units after $4.5 \mathrm{hr}$.

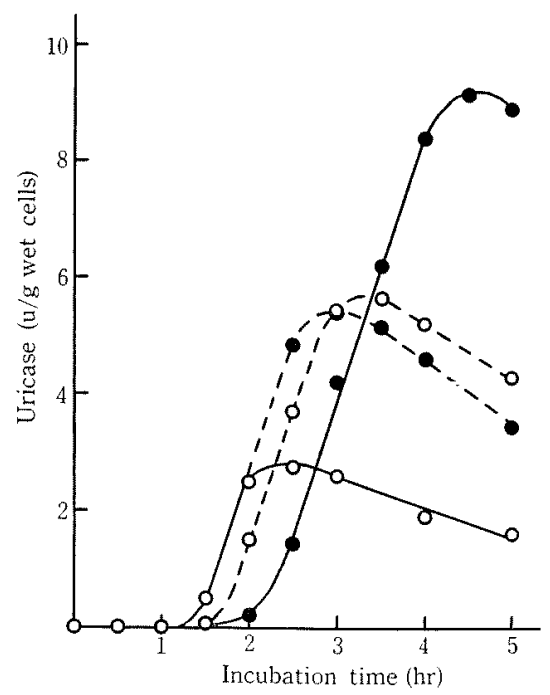

FIG. 2. Increase in Uricase Activity of the Cells Incubated with Various Purine Bases.

Uricase activity was assayed spectrophotometrically in sonic extracts of the cells incubated with urate $\mathrm{O}-\mathrm{O}$, xanthine --- 6,8-dihydroxypurine $\mathrm{O}-\mathrm{O}$ or hypoxanthine 


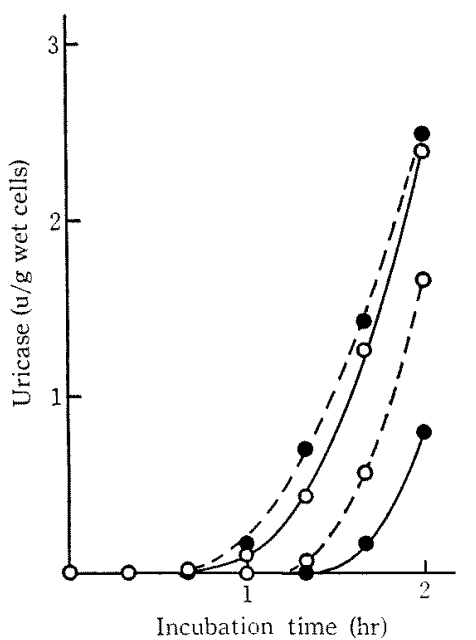

FIg. 3. Lag of Uricase Formation by the Cells Incubated with Various Purine Bases.

Uricase activity was assayed spectrophotometrically in sonic extracts of the cells incubated with urate $\mathrm{O}-\mathrm{O}$, xanthine --- 6,8-dihydroxypurine $\mathrm{O}-\mathrm{O}$ or hypoxanthine


In order to characterize the difference in lag period required for the induction of uricase formation in the cells by treatment with the purine bases, the activity was assayed at short term intervals during the first $2 \mathrm{hr}$ of incubation. As shown in Fig. 3, the shortest lag for the enzyme formation was observed in the cells incubated with xanthine. A longer lag period was required for the induction with 6,8-dihydroxypurine than the period with urate, and the lag was longest with hypoxanthine.

Changes in the level of purine bases in the incubation medium are shown in Fig. 4. This microorganism has been known to accumulate in medium certain intermediates of purine base catabolism. ${ }^{2,4)}$ When hypoxanthine was supplied to cells, xanthine and 6,8-dihydroxypurine were once accumulated in medium and then further oxidized. Urate was not or slightly, if any, released from the cells. On
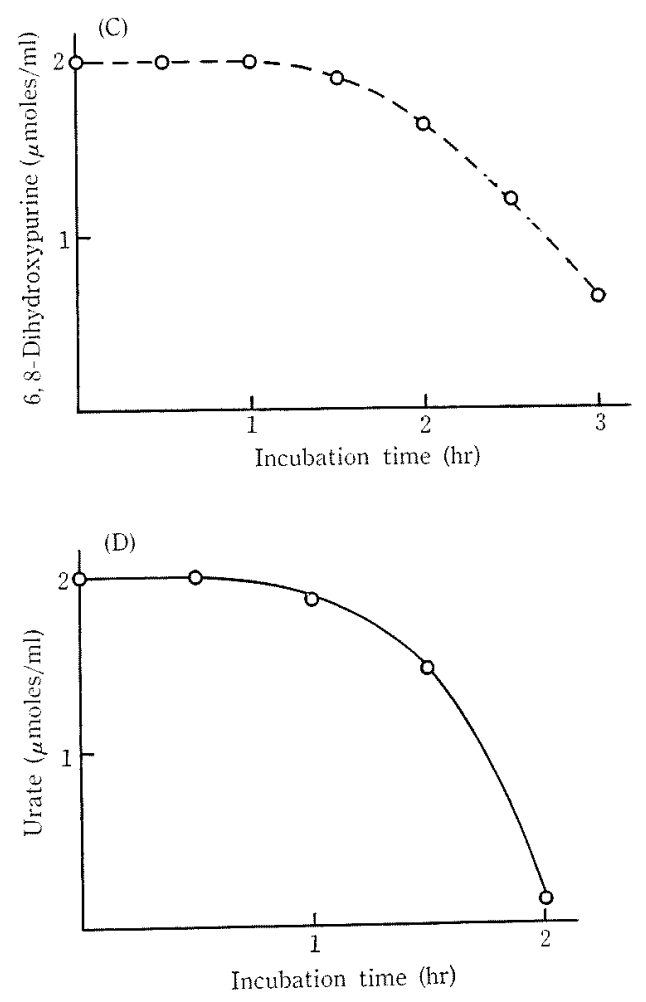

FIG. 4. Change in Purine Bases in the Incubation Medium. Hypoxanthine (A), xanthine (B), 6,8-dihydroxypurine (C) or urate (D) was added to the medium. Urate $\bigcirc-O$, xanthine $-6,8$-dihydroxypurine $\bigcirc-O$ and hypoxanthine $-\longrightarrow$ in the medium were determined by liquid chromatography. 


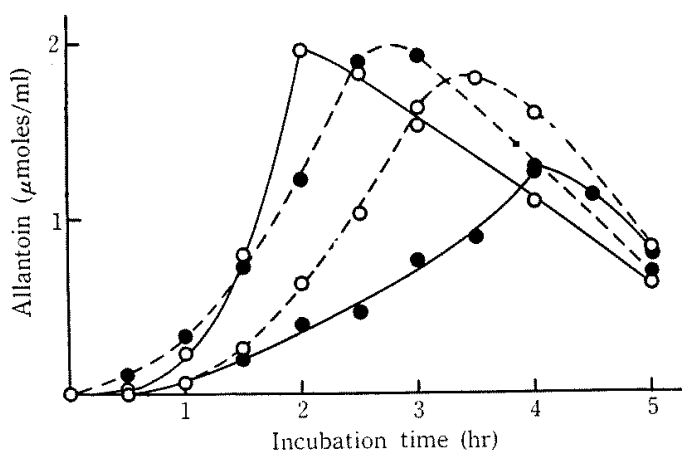

FIG. 5. Accumulation of Allantoin in the Medium in which Cells were Incubated with Various Purine Bases.

Allantoin was determined by liquid chromatography in the medium to which urate $0-0$, xanthine 6,8-dihydroxypurine 0 -- or hypoxanthine was added.

the contrary, a considerable fraction of urate was accumulated in medium before being further degraded when cells were incubated with xanthine. When cells were treated with urate or 6,8-dihydroxypurine, no other ultraviolet absorbing substance was detected in medium.

As shown in Fig. 5, allantoin was accumulated in all of the medium incubated with purine bases tested here. However, signifcant differences were observed in the mode of increase in allantoin depending on purine bases given to the medium. It was found, by comparing with Fig. 2, that the rate of allantoin accumulation increased significantly as uricase activity of cells increased when urate was added to medium. Increase in the rate of allantoin accumulation was also observed in the media incubated with xanthine and with 6,8-dihydroxypurine. In the medium supplied with hypoxanthine, on the contrary, the rate of accumulation was approximately constant for a long period of incubation, although uricase activity of cells increased markedly.

For the purpose of examining the effect on uricase formation of urate supplied to medium at a rate corresponding to that of generation of urate in the cells incubated with hypoxanthine, $1 \mu$ mole of urate was added at every
$6 \mathrm{~min}$ of incubation for $4 \mathrm{hr}$. This was calculated from the data shown in Fig. 5. Total amount of urate added was $40 \mu$ moles

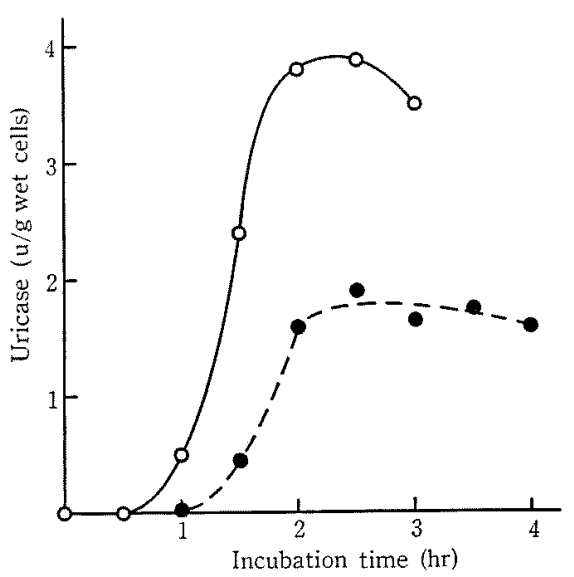

FIG. 6. Uricase Activity of the Cells to which Urate was Supplied Sparingly.

Forty micromoles of urate were devided into $1 \mu$ mole aliquots and added to the medium at zero time and at every $6 \mathrm{~min}-\cdots$, or were added all at once at zero time of incubation $\mathrm{O}-\mathrm{O}$. Uricase activity was assayed spectrophotometrically in sonic extracts of the cells taken at intervals.

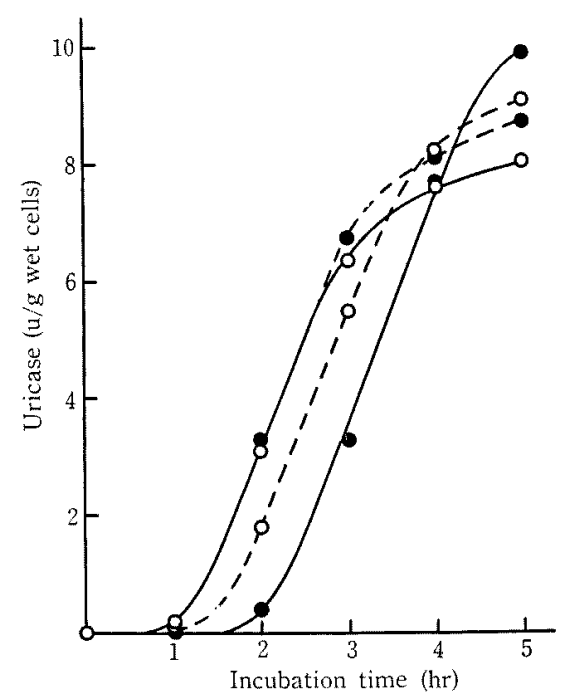

Fig. 7. Uricase Activity of the Cells Incubated with Various Purine Bases.

Cells were incubated with $24 \mu$ moles of urate $0-0$, $12 \mu$ moles of xanthine $-\cdots, 6$ moles of 6,8-dihydroxypurine $\bigcirc-\cdots$ or $3 \mu$ moles of hypoxanthine $-\bullet$. Uricase activity was assayed spectrophotometrically in sonic extracts of the cells taken at intervals. 
per $20 \mathrm{ml}$ of the medium. As a control, the same amount of urate was added all at once at the beginning of incubation. As shown in Fig. 6, uricase formation by the cells received urate in a sparing manner showed a longer lag than that by the cells given urate all at once. After the lag, uricase formation by the test cells became almost alike to that by the control cells, followed by a sudden cessation when the activity approached to 2 units per $g$ of cells. A longer lag period observed in uricase formation by the test cells may be accounted for the fact that the cells had almost no urate uptake activity at the beginning of incubation, ${ }^{3 \prime}$ and thus the entry of urate into the cells may be mainly mediated by simple diffusion and be dependent on the concentration of urate in medium.

The concentration of purine bases in medium was so raised that they could remain in medium for at least $4 \mathrm{hr}$ of incubation. The initial concentration of urate was $24 \mathrm{~mm}$, xanthine $12 \mathrm{~mm}, 6,8$-dihydroxypurine $6 \mathrm{~mm}$ and hypoxanthine $3 \mathrm{~mm}$. As shown in Fig. 7, the amount of uricase produced became approximately equal in the cells incubated with these purine bases.

\section{DISCUSSION}

Uricase formation of a strain of Streptomyces sp. seems to be derepressed in the cells incubated in a medium deprived of nitrogen source, and is promoted by urate, xanthine, 6,8-dihydroxypurine and hypoxanthine supplied to the medium. The enzyme, however, was produced in noticeably different amounts, increasing in the following order of purine bases added to medium: urate, xanthine, 6,8-dihydroxypurine and hypoxanthine, if they were added to give an equal molar concentration at the beginning of incubation. The differences observed in lag time of uricase formation, in accumulation of intermediate products and in production of allantoin by the cells incubated with these purine bases, shown in Figs. 3, 4 and 5, appear to indicate that they can serve as an inducer of uricase formation only after being converted to urate. It could not be the case, therefore, that the cells incubated with xanthine, 6,8-dihydroxypurine or hypoxanthine produce larger amount of uricase than those incubated with urate, because these purine bases act as an inducer in addition to urate.

Although the amount of uricase produced varied considerably in the cells incubated with these purine bases, the rate of the enzyme formation appeared to be essentially identical (about 4 units per $g$ of cells per hr) in its maximum as seen from Fig. 2. Therefore, the diversity in quantity of uricase produced seems to arise from the diversity in duration of the enzyme production at its maximum rate. Uricase formation by the cells has been shown to continue as far as urate remains in medium, ${ }^{1}$ or, in other words, as far as the inducer is available to cells. Consequently, the duration of uricase formation in the cells treated with various purine bases may be based on the availability of the inducer drived from the purine bases.

Urate may be generated in cells by either transporting it from medium or by oxidizing its precursors in cells. Since this microorganism has been known not to accumulate urate in cells but to accumulate allantoin in medium, ${ }^{1,5)}$ the mode of appearance of allantoin in medium may represent the mode of generation of urate in cells. As shown in Fig. 5, urate appears to be generated in cells in considerably different manners depending on purine bases supplied to the cells. Although the cells incubated with hypoxanthine seemed to be provided with urate in a much slower rate (about $10 \mu$ moles per $\mathrm{hr}$ ) than those treated with other purine bases, the concentration of urate in the cells might be maintained high enough for inducing uricase formation, since the rate of uricase formation is nearly identical with that in the cells receiving the other purine bases. However, as seen from Fig. 6, urate given to cells from medium at this rate failed to induce the enzyme formation when the activity increased to a certain level. It seems, therefore, that the quantity of urate, 
when supplied to cells from medium, should be larger than that corresponding to the activity of uricase in the cells, in order that it may act effectively as the inducer of uricase formation, in contrast to urate supplied within cells, which could serve as the inducer efficiently even in the presence of a large amount of the enzyme.

It may be considered, from these facts, that there is a difference in "effectiveness" or "efficiency" as the inducer of uricase formation between urate provided to cells intracellularly and extracellularly. A portion of exogenous urate seems to be degraded by uricase before serving as inducer, and this portion appears to increase as uricase activity increases. The portion of endogenous urate, on the contrary, which can act as the inducer seems not to be affected by the activity. Segregation of endogenous and exogenous urate molecules might be accomplished by intracellular compartmentalization that distinguishes the site of urate oxidation and that of uricase induction. And thus the urate molecules originated from outside of cells would be more susceptible to uricase reaction than those generated within the cells before acting as inducer of uricase formation. This might decrease the "efficiency" of exogenous urate as inducer for uricase formation. Segregation of endogenous and exogenous metabolites by intracellular compartmentalization has been reported for several microorganisms. ${ }^{6 \sim 10}$
This microorganism has been found to convert hypoxanthine to IMP and probably to other nucleotides when the cells are actively growing.* Although the majority of hypoxanthine has been shown to be oxidized to urate under the conditions employed, ${ }^{4)}$ a fraction of the purine base could be converted to the nucleotides. The effect of these nucleotides on uricase formation should be clarified in connection with the pronounced increase in uricase activity in the cells incubated with hypoxanthine, since it has been found that uricase formation of the cells grown in the peptone-glucose medium was derepressed in the presence of hypoxanthine. ${ }^{1)}$

\section{REFERENCES}

1) Y. Watanabe, M. Yano and J. Fukumoto, Agr. Biol. Chem., 33, 1282 (1969).

2) Y. Watanabe and J. Fukumoto, ibid., 34, 1625 (1970).

3) Y. Watanabe, ibid., 35, 2008 (1971).

4) Y. Watanabe and T. Ohe, ibid., 36, 785 (1972).

5) Y. Watanabe, M. Yano and J. Fukumoto, ibid., 36, 1 (1972).

6) E. E. Sercarz and L. Gorini, J. Mol. Biol., 8, 254 (1964).

7) H. Tabor and C. W. Tabor, J. Biol. Chem., 244, 6383 (1969).

8) H. H. Winkler, J. Bacteriol, 101, 470 (1970).

9) L. G. Williams, S. A. Bernhardt and R.H. Davis, J. Biol. Chem., 246, 973 (1971).

10) G. W. Dietz and L. A. Heppel, ibid., 246, 2885 (1971). 